\title{
$1^{1} \mathrm{H}$ NMR Spectrum
}

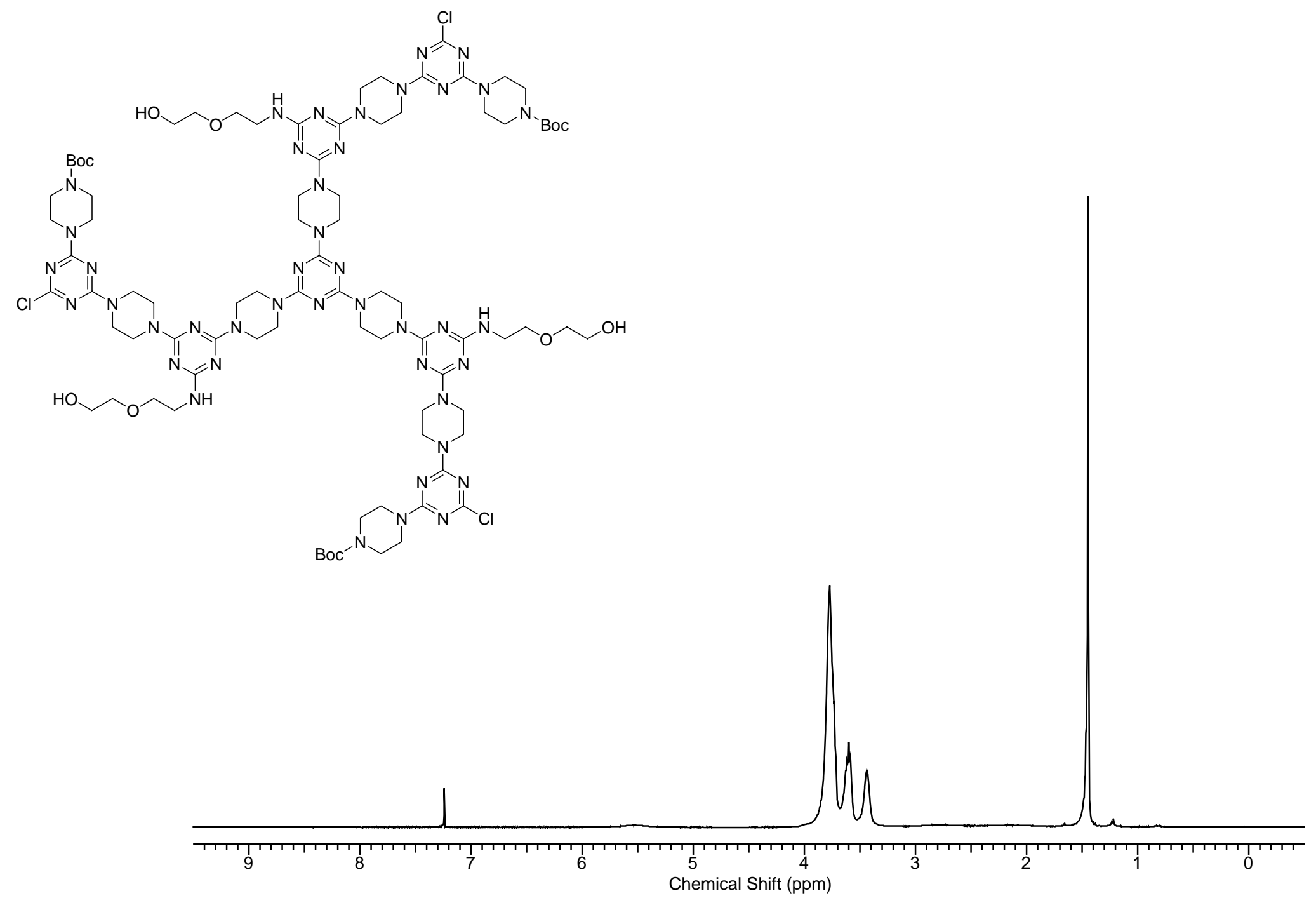




\section{$1{ }^{13} \mathrm{C}\left\{{ }^{1} \mathrm{H}\right\}$ NMR Spectrum}

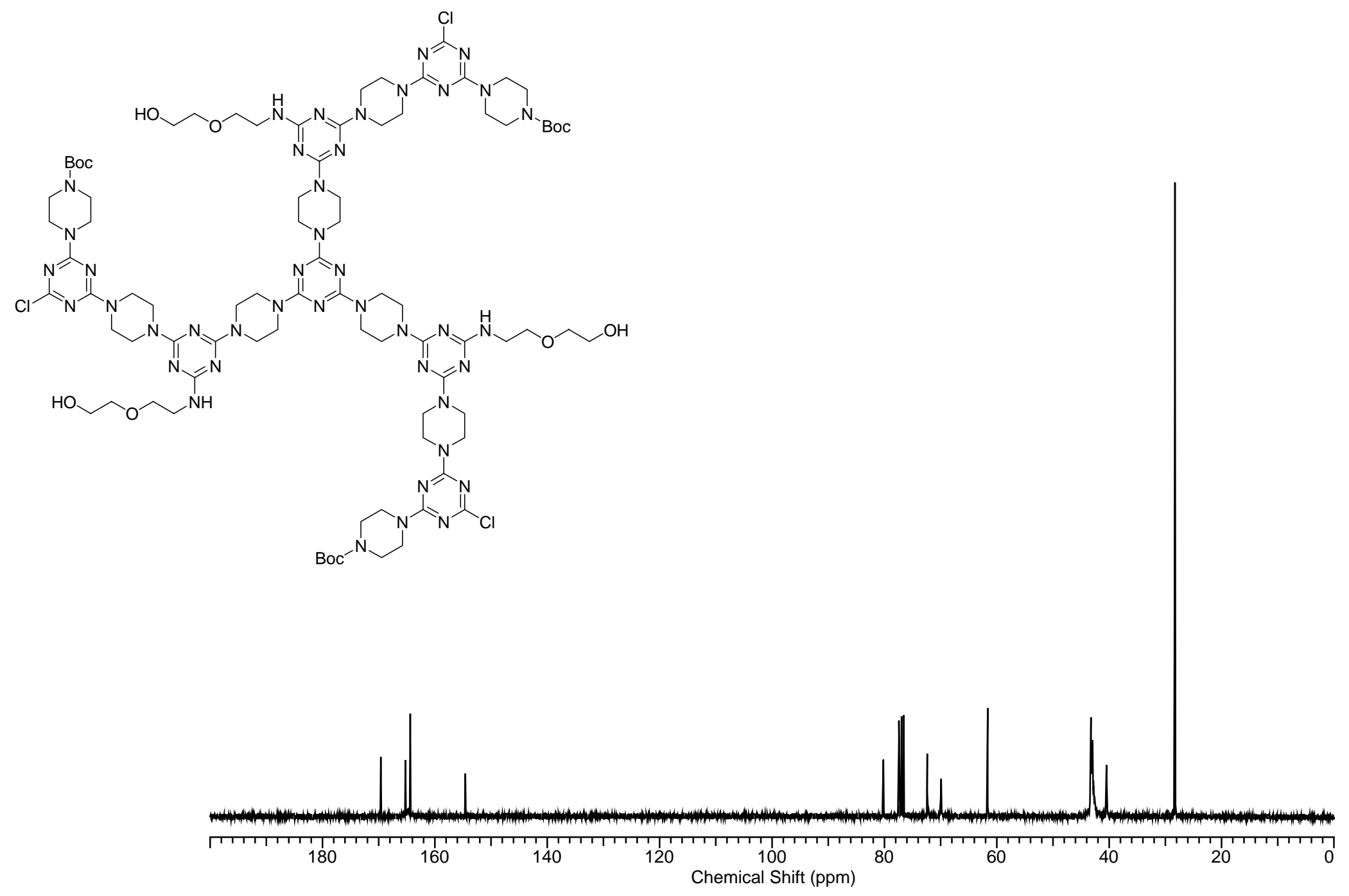


1 MALDI-MS
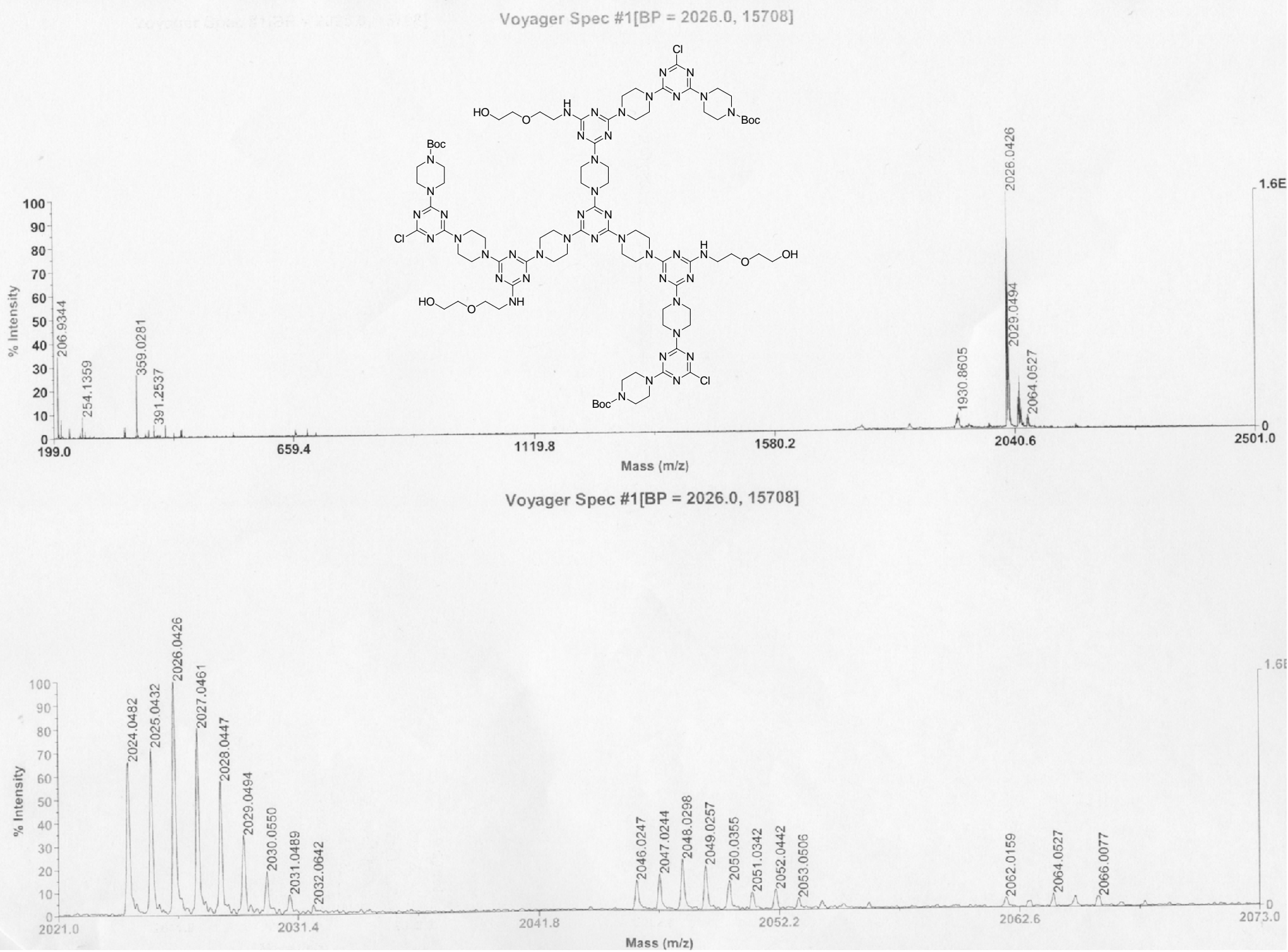


\section{$2{ }^{1} \mathrm{H}$ NMR Spectrum}

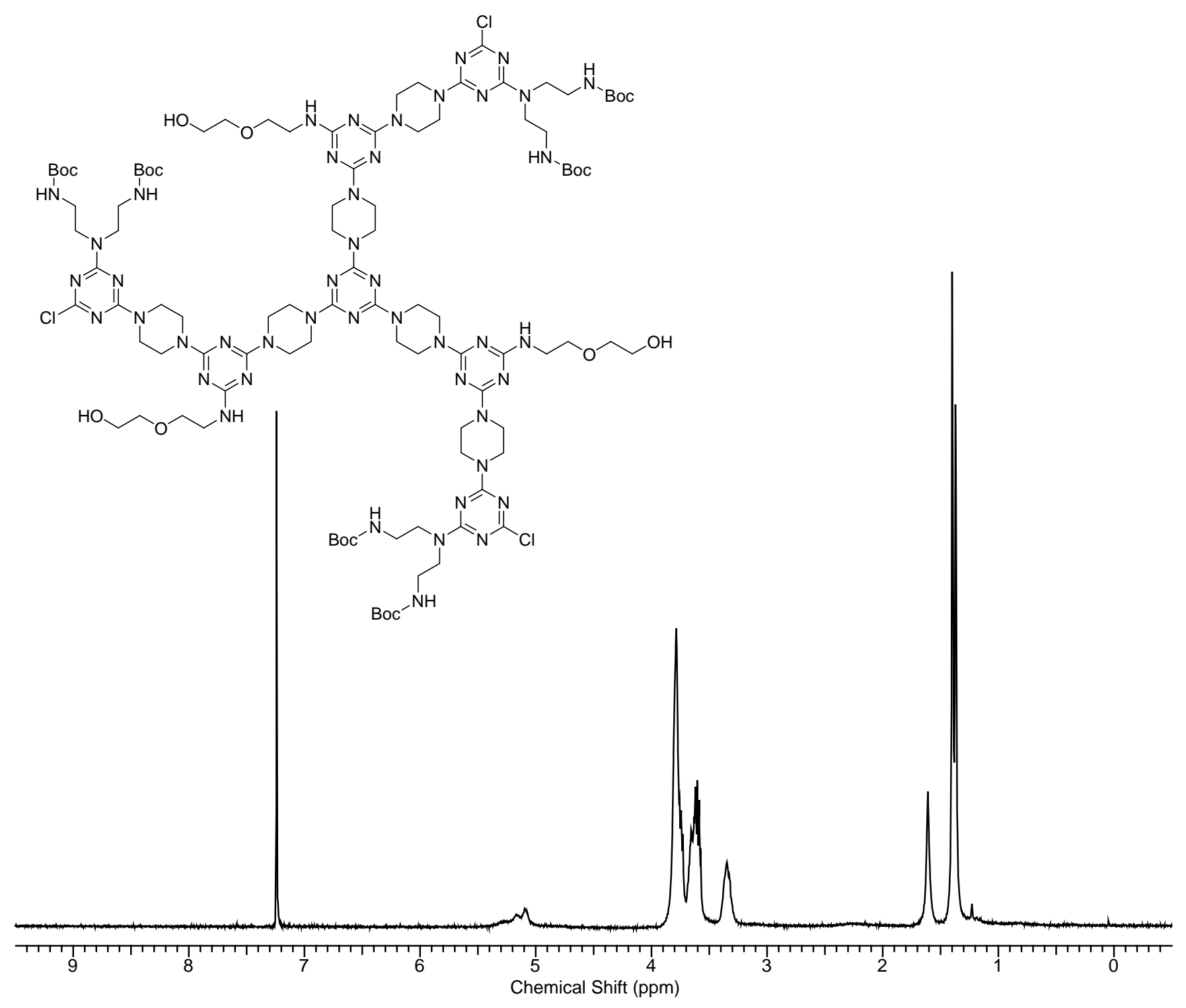




\section{$2{ }^{13} \mathrm{C}\left\{{ }^{1} \mathrm{H}\right\}$ NMR Spectrum}

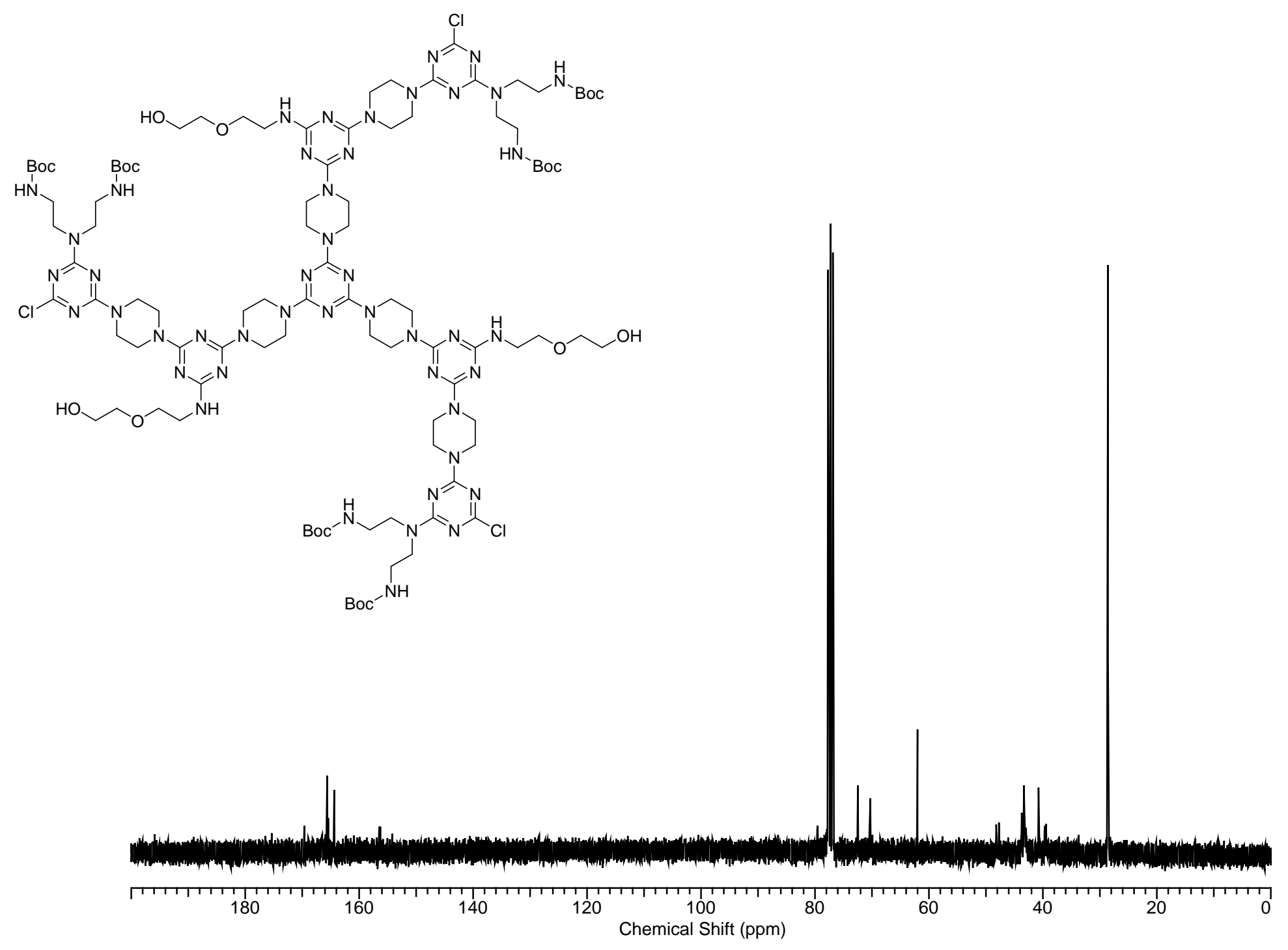




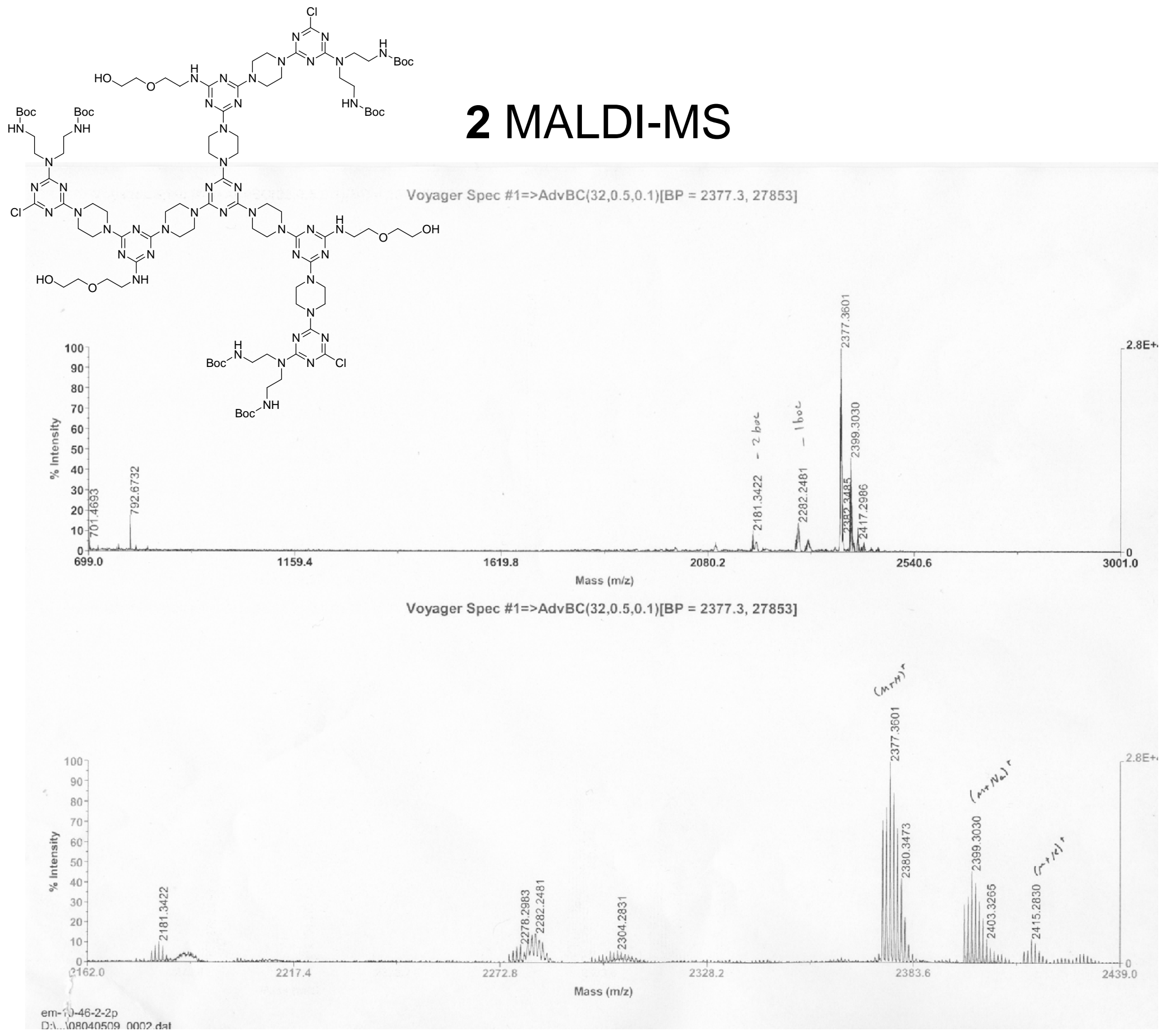




\section{$3{ }^{1} \mathrm{H}$ NMR Spectrum}

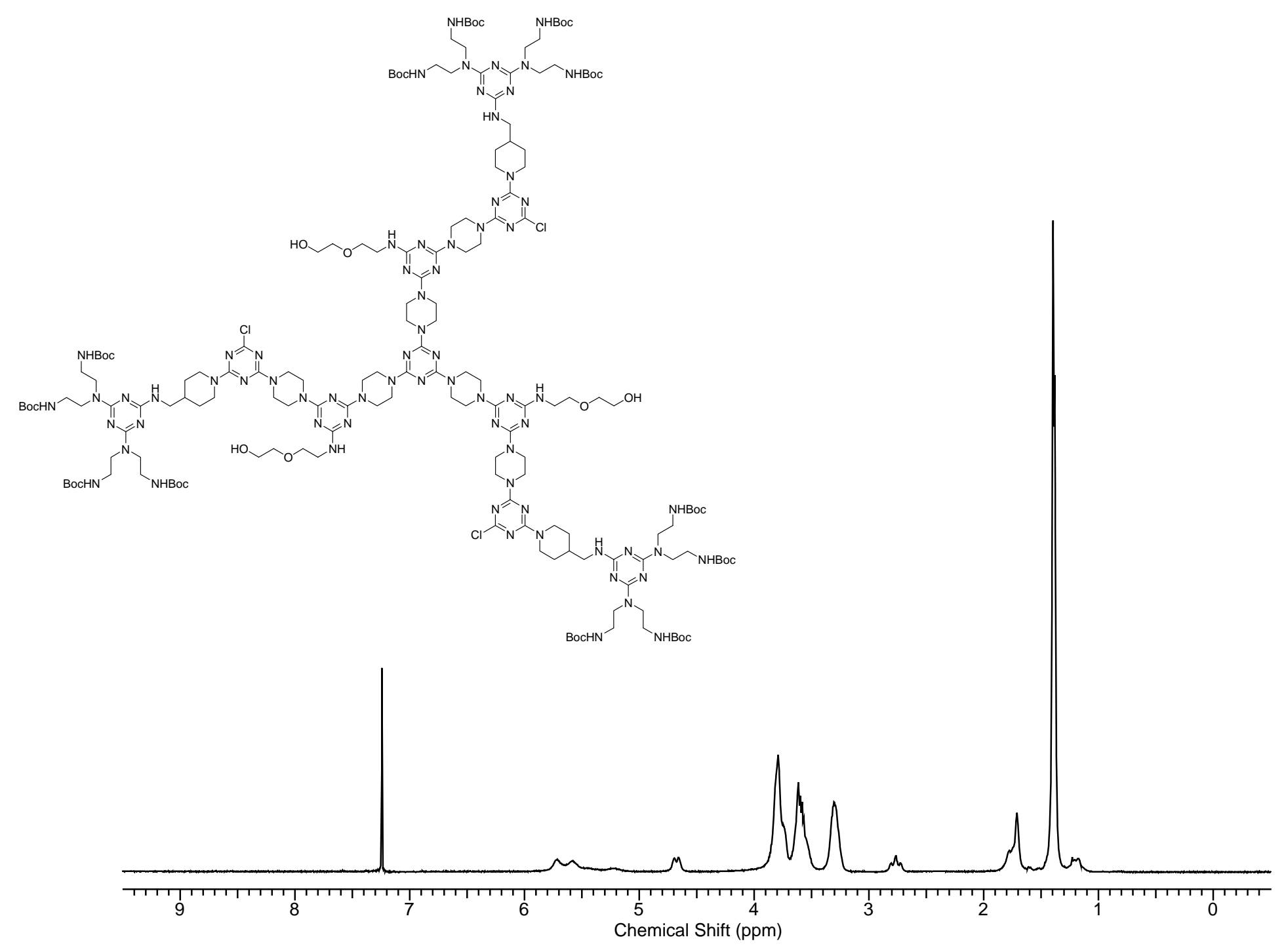




\section{$3^{13} \mathrm{C}\left\{{ }^{1} \mathrm{H}\right\}$ NMR Spectrum}

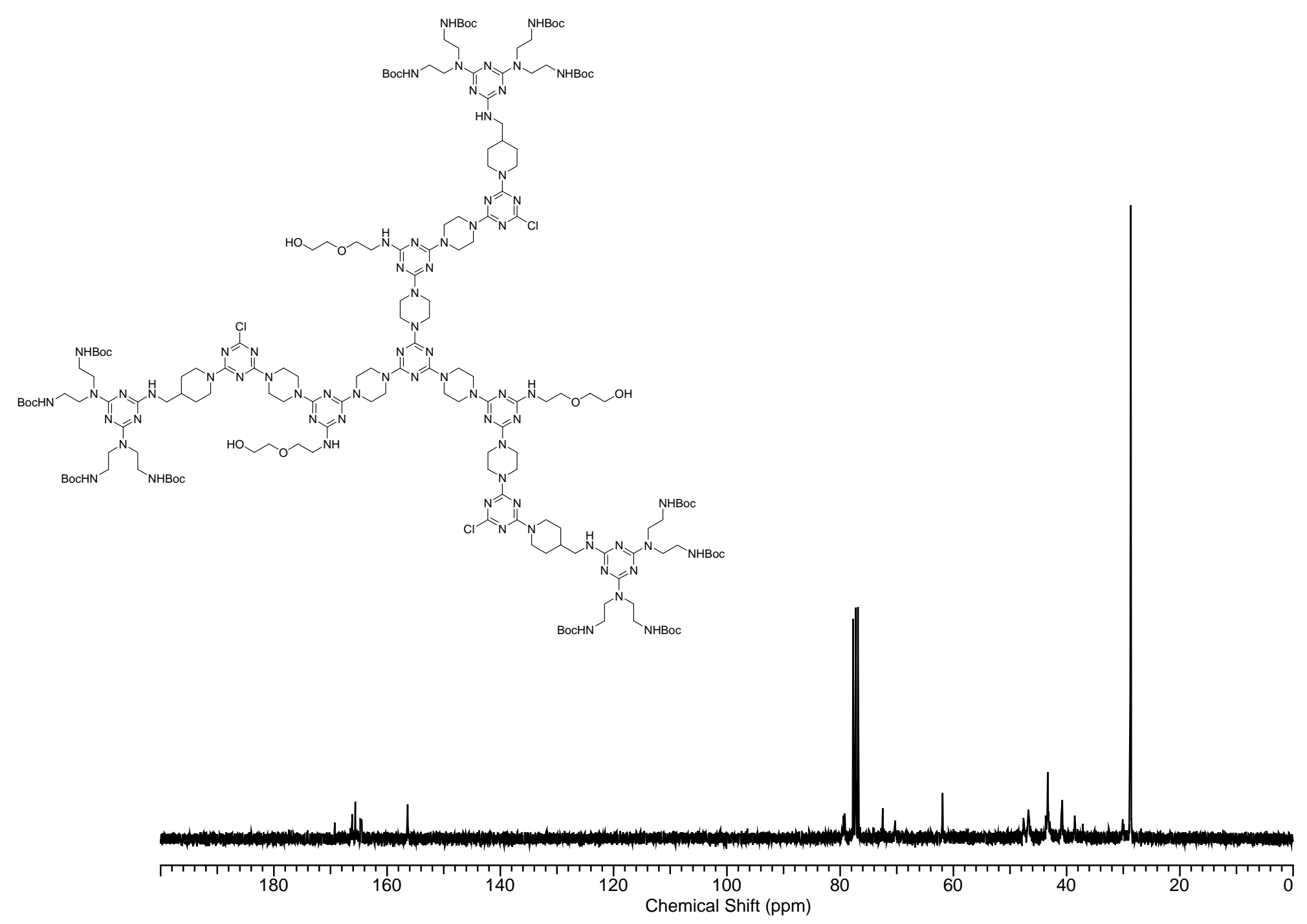




\section{MALDI-MS}

Voyager Spec \#1 $=>A d v B C(32,0.5,0.1)[B P=663.5,3928]$
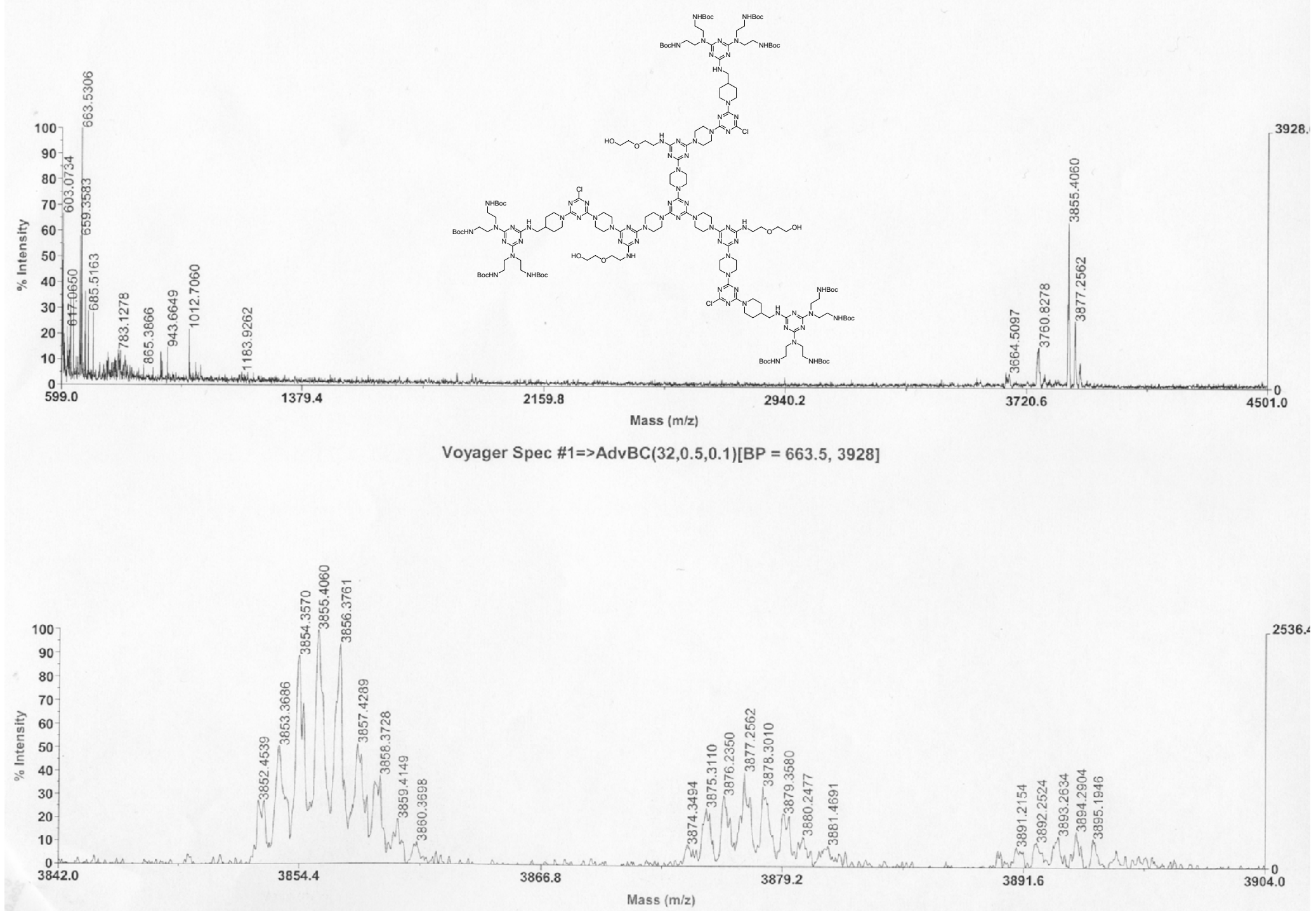


\section{$4^{1} \mathrm{H}$ NMR Spectrum}
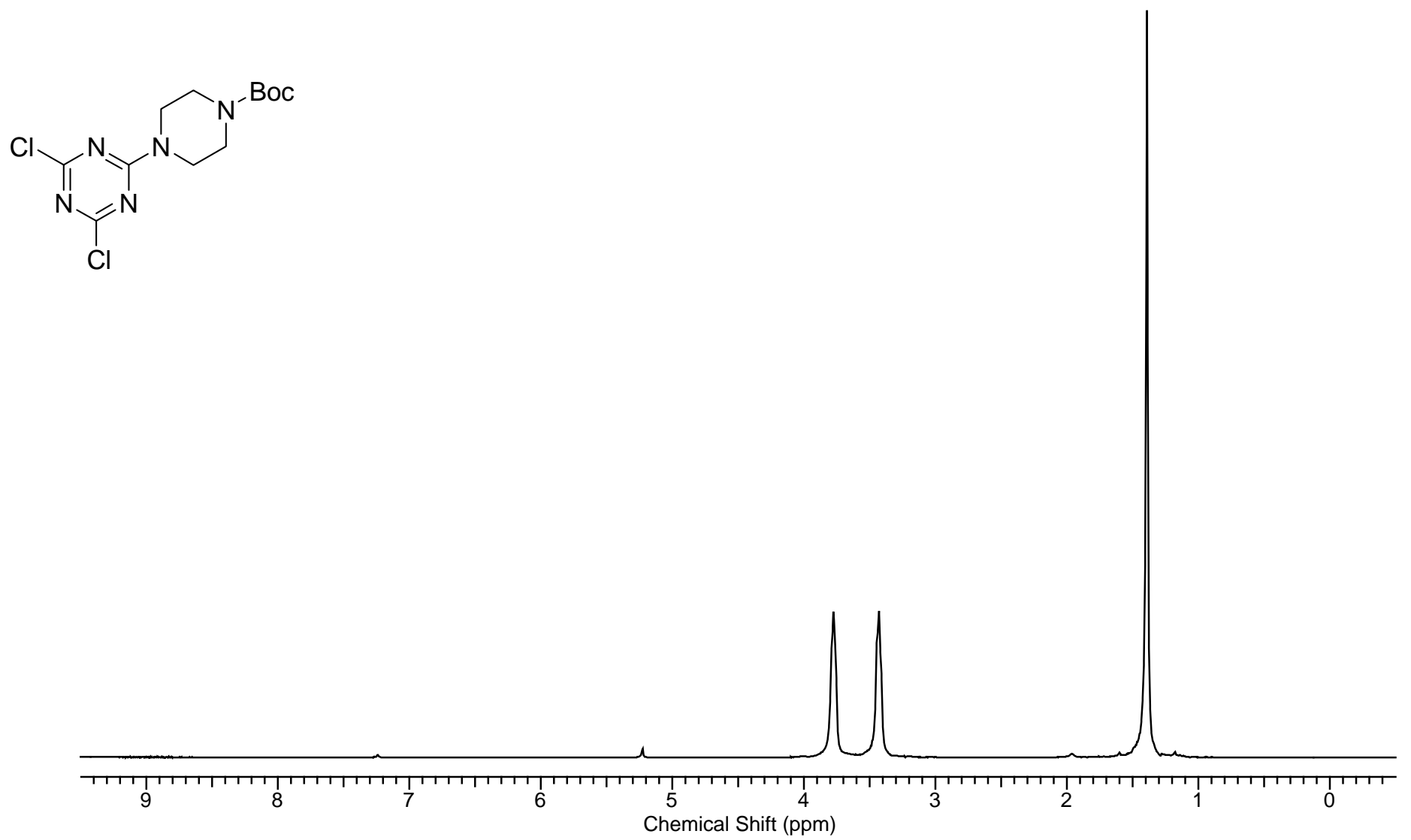


\section{$4{ }^{13} \mathrm{C}\left\{{ }^{1} \mathrm{H}\right\}$ NMR Spectrum}
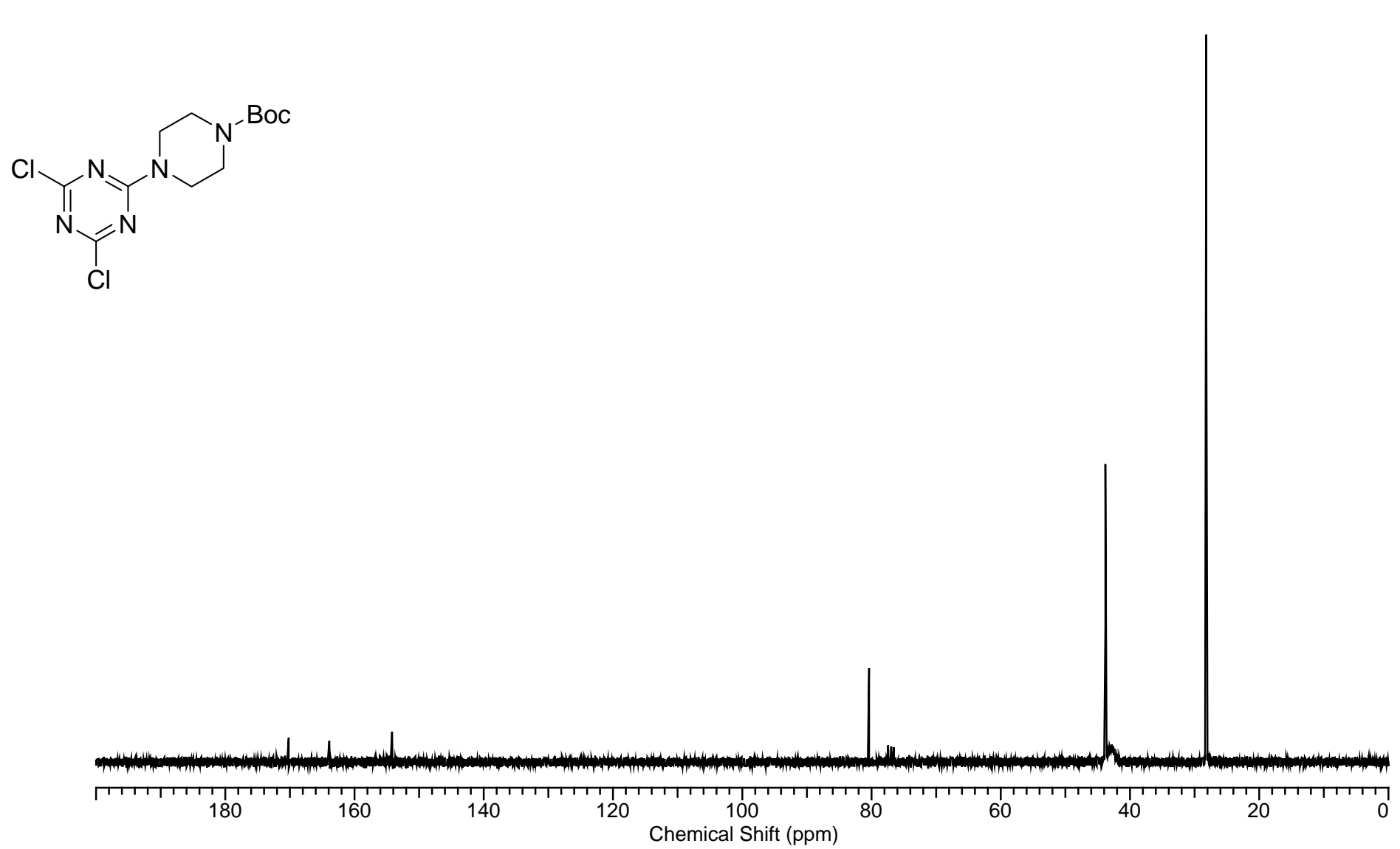


\section{ESI-MS}

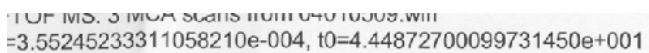

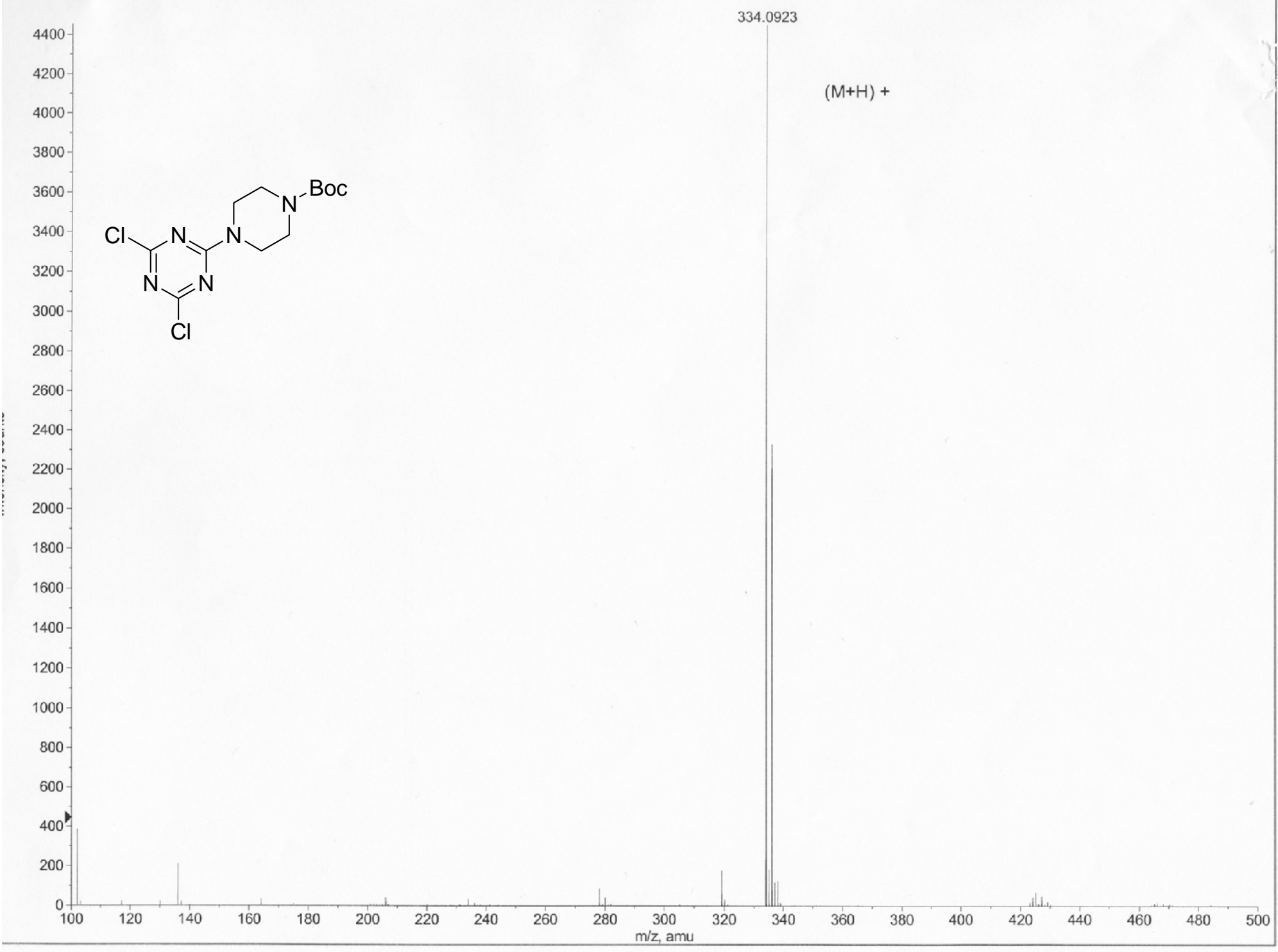




\section{$5{ }^{1} \mathrm{H}$ NMR Spectrum}
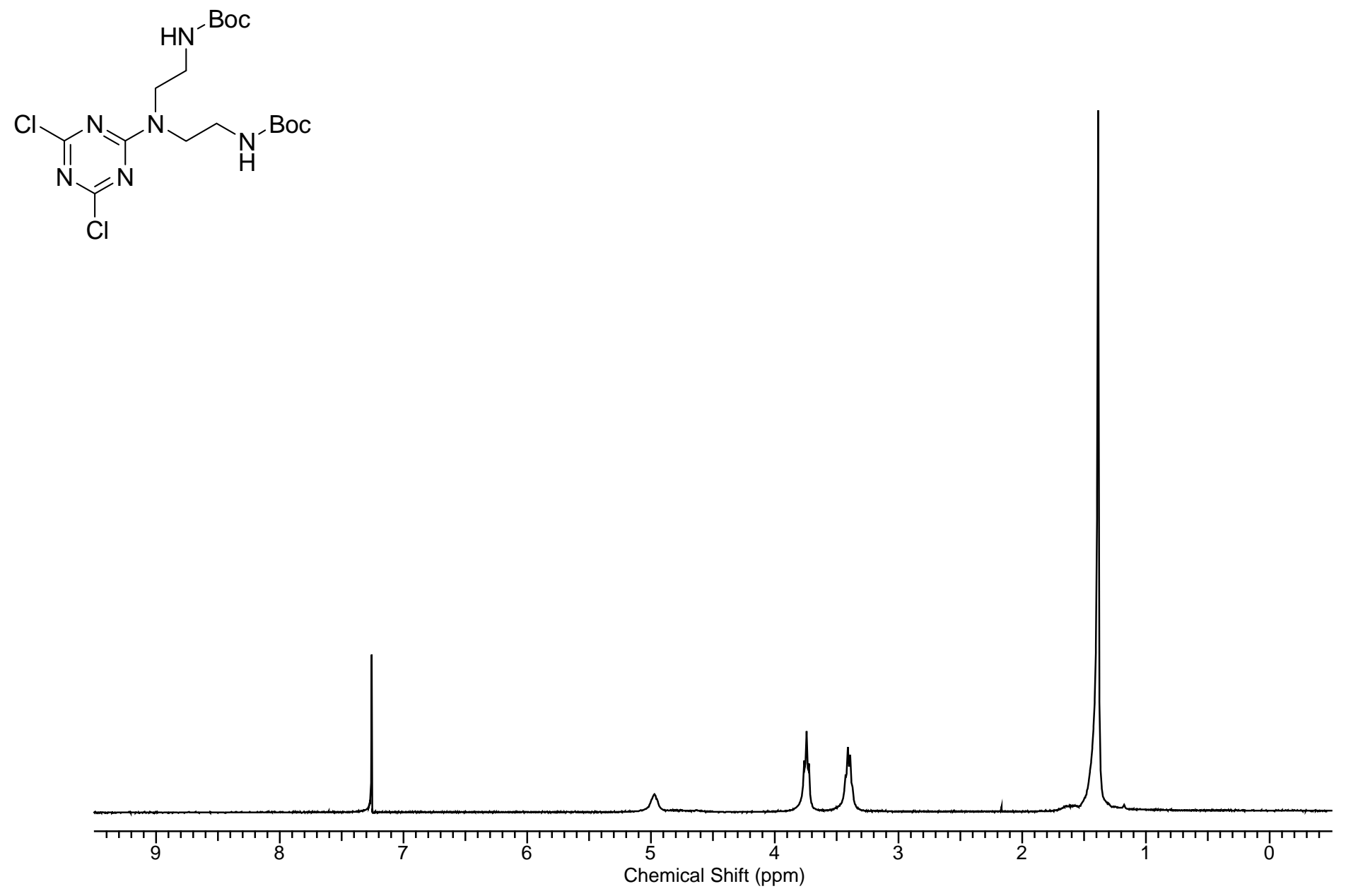


\section{$5{ }^{13} \mathrm{C}\left\{{ }^{1} \mathrm{H}\right\}$ NMR Spectrum}
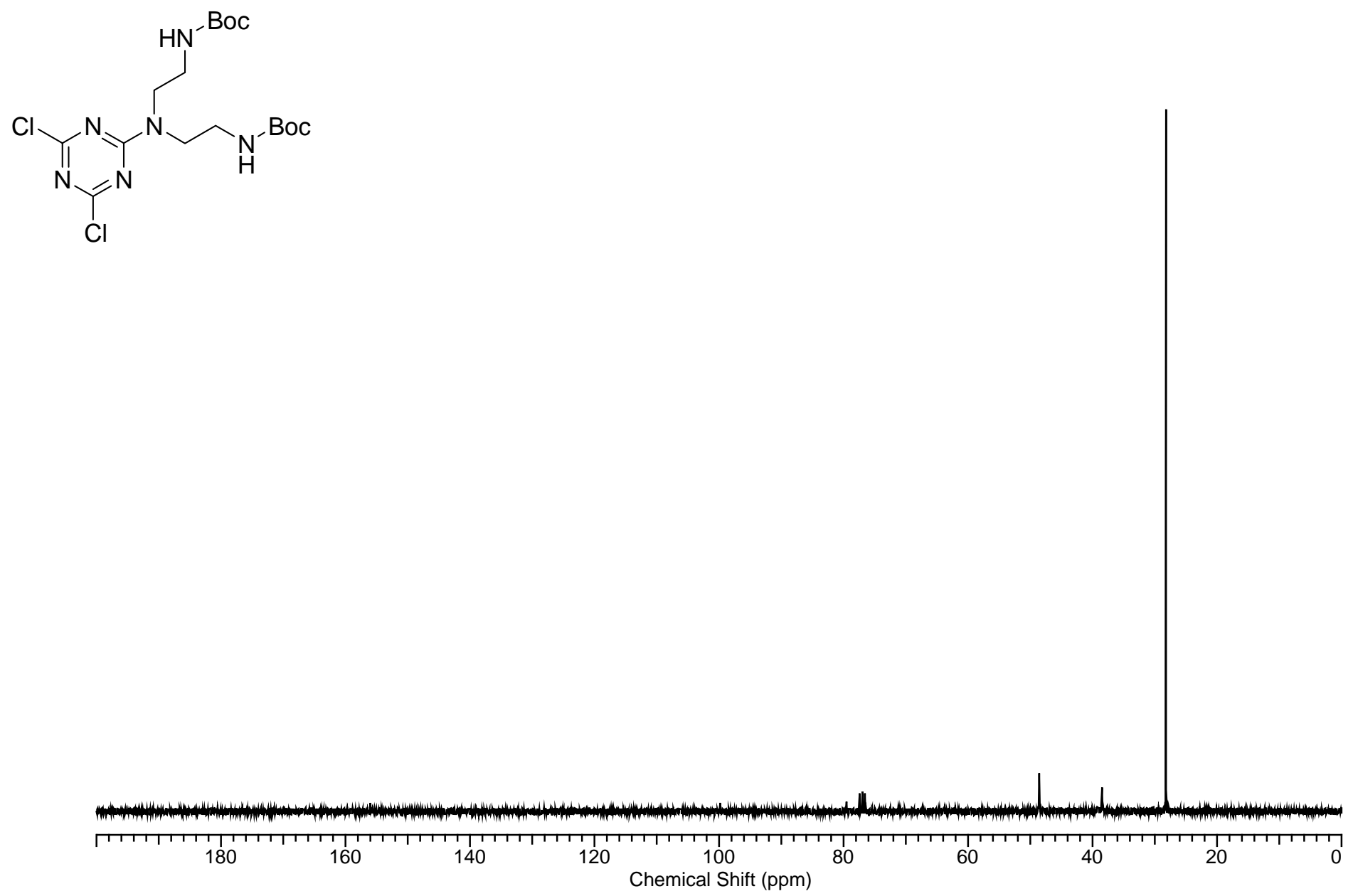


\section{ESI-MS}

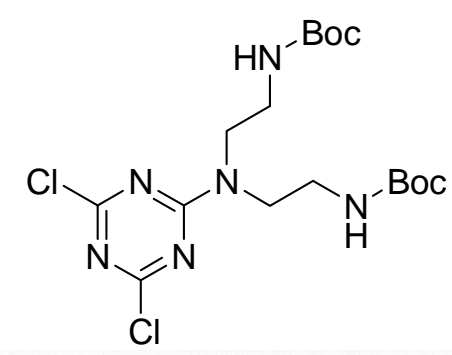

+TOF MS: 6 MCA scans from 07110509. wiff

Max. 683.0 counts.

$a=3.55269554620941690 \mathrm{e}-004$, to $=4.51489113079805970 \mathrm{e}+001$

451.1613

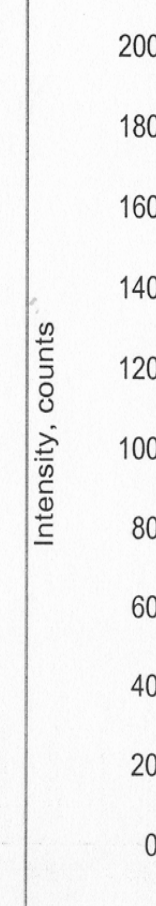

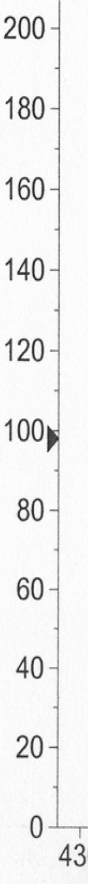

$\begin{array}{llllll}432 & 434 & 436 & 438 & 440\end{array}$

442

446

453.1580
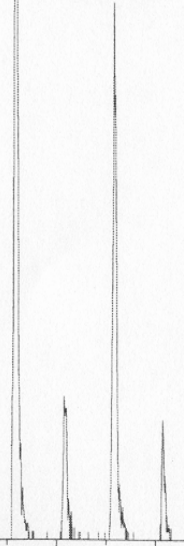

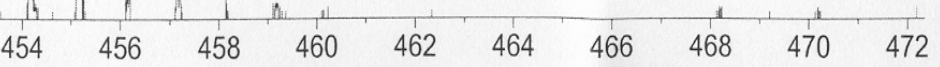




\section{$6{ }^{1} \mathrm{H}$ NMR Spectrum}

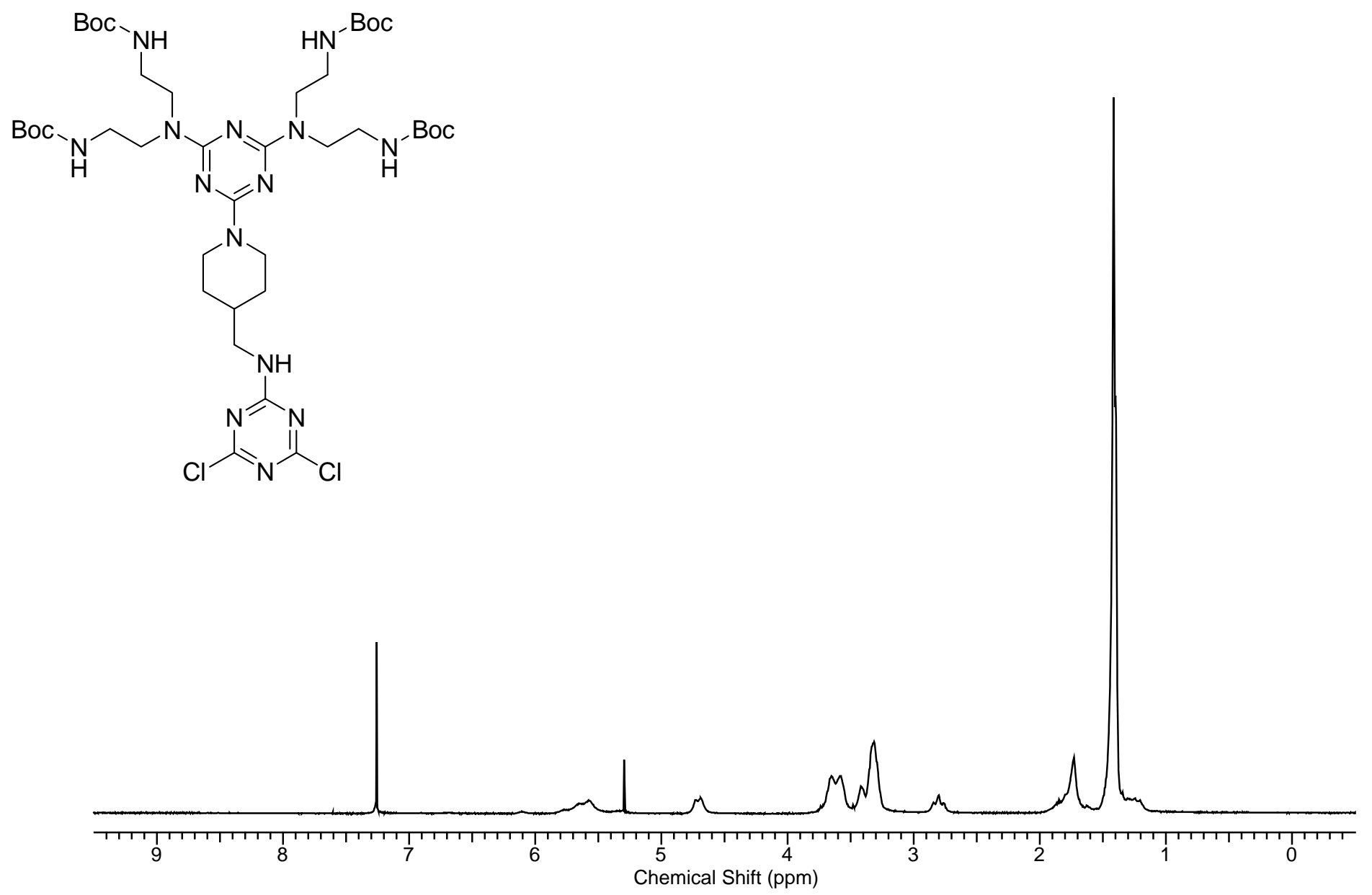




\section{$6{ }^{13} \mathrm{C}\left\{{ }^{1} \mathrm{H}\right\}$ NMR Spectrum}
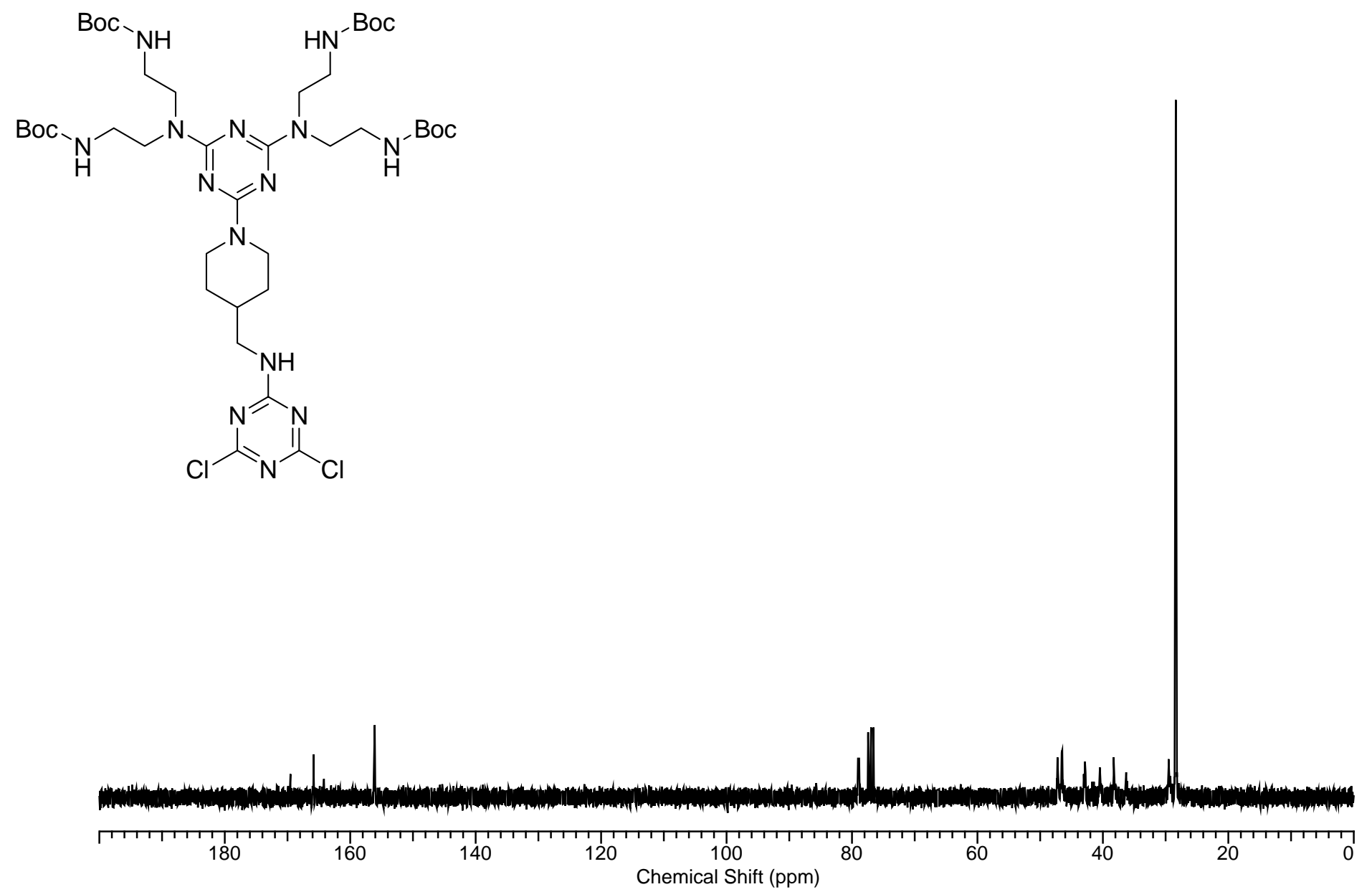


\section{ESI-MS}

Voyager Spec \#1[BP = 943.6, 13018]
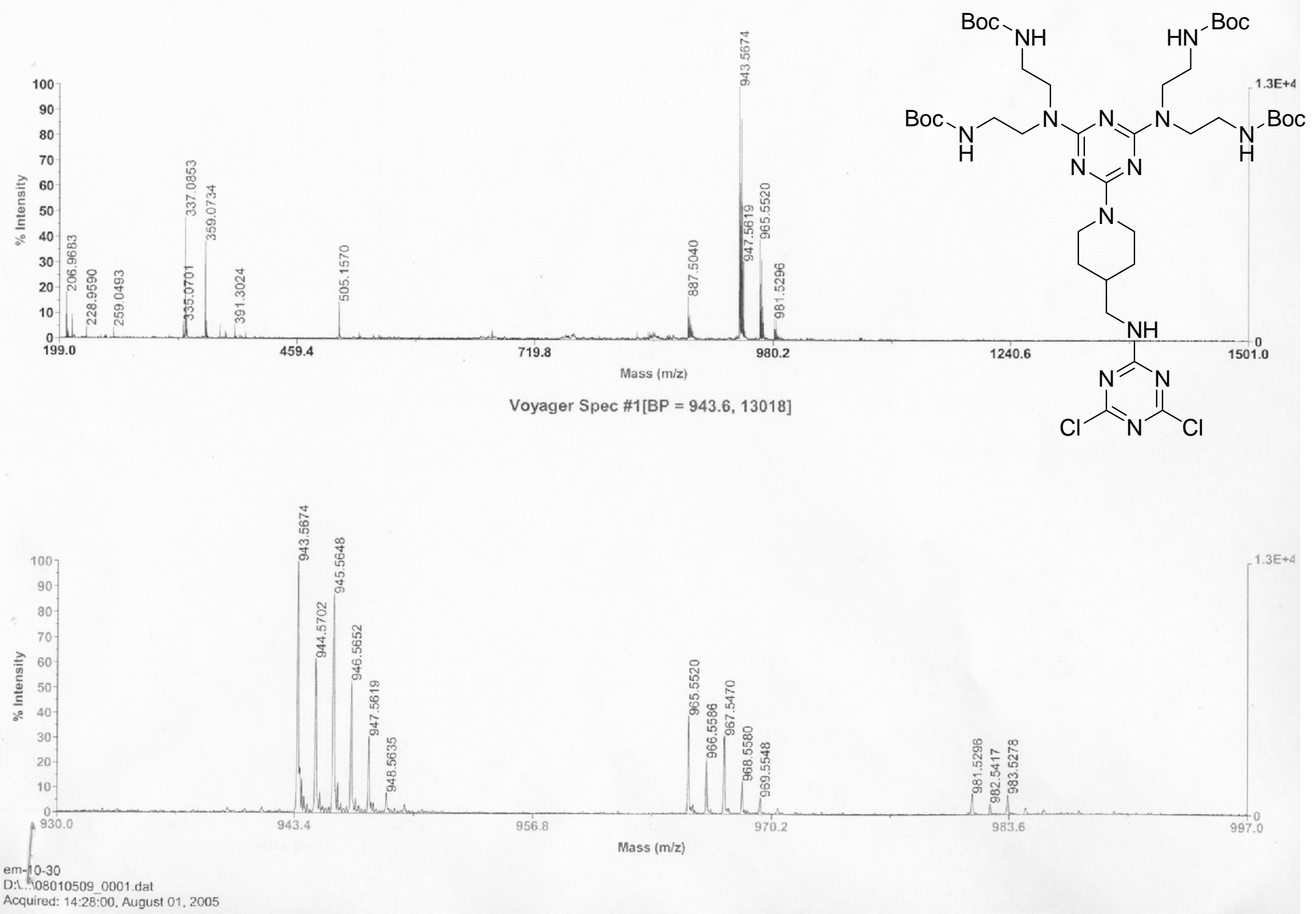